\title{
ANTIBACTERIAL ACTIVITY AND ANTIOXIDANT ACTIVITY OF
}

\section{CARICA PAPAYA ON SOME ENTERIC BACTERIAL ISOLATES}

\section{OF PUBLIC HEALTH IMPORTANCE}

\author{
R. K. SUMATHI ${ }^{1} \&$ SINDOOJA. S \\ ${ }^{1}$ Associate Professor, Department of Microbiology, Sri Ramakrishna College of Arts and Science
} for Women, Tamil Nadu, India

${ }^{2}$ PG Student, Department of Microbiology, Sri Ramakrishna College of Arts and Science for Women, Tamil Nadu, India

In the present study, ethanol extract and aqueous extract of Carica papaya in different concentration were evaluated for the antimicrobial properties against Enteric pathogenic organisms such as Escherichia coli, Shigella sp., Klebsiella sp., and Pseudomonas sp., by using agar well diffusion method. The extracts were screened for the phytochemical constituents using standard procedure. The anti-oxidant activity of ethanol and aqueous extract fractions from the leaf of papaya were evaluated and ethanol extract showed the strong DPPH activity, Nitric oxide radical scavenging assay, Ferric Reducing/Antioxidant Power (FRAP) Assay and Hydrogen Peroxide Scavenging Activity $\left(\mathrm{H}_{2} \mathrm{O}_{2}\right)$. The leaves of papaya and these compounds might be used as natural antioxidants. Antibacterial activity against the test isolates was an indication of the possibility of sourcing alternative antibiotic substances in these plants for the production of newer antibacterial agents.
\end{abstract}

KEYWORDS: Antibacterial Activities, Carica Papaya, Antioxidant \& Enteric Bacteria

Received: Jul 11, 2018; Accepted: Aug 01, 2018; Published: Oct 10, 2018; Paper Id.: IJBRDDEC20183

\section{INTRODUCTION}

According to WHO, around 21,000 plant species have the potential for being used as medicinal plants. Many studies have been conducted to evaluate the biological activities of various parts of Carica papaya. The two important compounds are chymopapain and papain, which aid in digestion. The fruit and seed of Carica papaya have showed bacteriostatic activity against several enteropathogens in human. Phytochemical studies on the leaves of Carica papaya shows the presence of various compounds, including piperidine alkaloids such as carpaine, pseudocarpaine, and dehydrocarpaines I and II. Recently carpaine, quinic acid, six malic acid derivatives and four flavonoid glycosides in the leaf extract was identified. Carica papaya Linn. (Family: Caricaceae) primarily cultivated for its fruit and the young leaves are consumed as a vegetable. Different parts of the plant have been used in traditional medicine to treat various diseases. The principle for inhibiting the disease causing organism is by binding their protein molecules, acting as chelating agents (selective binding polyvalent metal ions so that the latter loses its biological activities), altering their biochemical systems, preventing the utilization of available interest to the microorganism and other causes inflammation analysis of microbial cells (Garrod et al., 1995). However, a very important step in the screening of the sanitizing and preservative activity of a plant material was to evaluate its antimicrobial properties. The importance of evaluation of the antimicrobial 
properties of Carica papaya leaves on some selected microorganisms and also to verify its minimum inhibitory concentration. The active components in this trait are expected to be unfriendly to the growth of at least some microorganisms, especially the disease causing, such as Escherichia coli, Pseudomonas species, Klebsiella species and Shigella species. Therefore, in this study the antimicrobial and antioxidant properties of the leaf of Carica papaya will be discussed.

\section{MATERIALS AND METHODS}

\section{Collection of Plant Materials}

The young leaves of Carica papaya are used in the research. Which were collected from the local area of Coimbatore. Identification and authentication of the plant material have been done at a Herbarium unit in the Botanical survey of India, Coimbatore with the following voucher numbers 1877. The samples were then washed and rinsed with distilled water. Samples are air-dried for 2-3 weeks. The dried leaves were made into powder by using mortar and pestle. Maceration method was described by Mukhtar and Tukur (1999). The powder was collected and stored in zip-lock polythene air-tight bag.

\section{Preparation of Plant Material}

The leaf of Carica papaya was separately extracted with hot water and $95 \%$ ethanol. These were prepared using the method as described by Oyagae et al., 1999.

\section{Test Organisms}

Clinical isolates of Escherichia coli, Pseudomonas sp, Kelbsiella sp, and Shigella sp, were obtained from the Department of Microbiology of Sri Ramakrishna Hospital, Coimbatore. Identification of the isolates was done by standard microbiological procedures (Cappuccino, 2014). The antimicrobial potency of the leaf extract was evaluated using the four bacterial strains causing food poisoning disease. The potential effectiveness of the extract can be used as a natural alternative to control food poisoning.

\section{Preparation of Plant Extract}

The ethanol and aqueous extract of plant sample was carried out by suspending $25 \mathrm{grams}$ of the finely ground leaves in 150 milliliter of distilled water and $95 \%$ ethanol. The hot water extraction was done at $80^{\circ} \mathrm{C}$ in soxhlet apparatus for $1 / 2$ hours. The ethanolic extraction was then filtered through a Whatman filter paper. The filtered extract was then sterilized using a membrane filter and were stored in the refrigerator at $4^{\circ} \mathrm{c}$ until used (Omojosola and Awe, 2004).

\section{Estimation of Antioxidant Activity \\ DPPH Radical Scavenging Activity}

The free radical scavenging activity of ethanolic and aqueous extract of the plant extract was measured by using 2 , 2-diphenyl-1-picrylhydrazyl (DPPH). The scavenging activity for DPPH free radicals was measured according to the procedure described by (Braca et al., 2001). An aliquot of $3 \mathrm{ml}$ of $0.004 \%$ DPPH solution in methanol and 0.5 to $2.5 \mu 1$ of plant extract/ascorbic acid at various concentrations were mixed. The mixture was shaken vigorously and allowed to reach a steady state at room temperature for $30 \mathrm{~min}$. Decolorization of DPPH was determined by measuring the absorbance at $517 \mathrm{~nm}$. A control was prepared using $0.1 \mathrm{ml}$ of the respective vehicle in the place of plant extract/ascorbic acid. The percentage inhibition of DPPH radicals by the extract/compound was determined by comparing the absorbance values 


\section{Nitric Oxide Radical Scavenging Assay (Garrat., 1964)}

The determination of Nitric oxide scavenging activity of the sample was determined byadding $400 \mu \mathrm{L}$ of $100 \mathrm{~mm}$ sodium nitroprusside, $100 \mu \mathrm{l}$ of Phosphate buffered saline $(\mathrm{pH}-7.4)$ and $100 \mu \mathrm{l}$ of different concentration of plant extracts. This reaction mixture was kept for incubation at $25^{\circ} \mathrm{C}$ for 150 minutes. To $0.5 \mathrm{ml}$ of the above solution, $0.5 \mathrm{ml}$ of Griess reagent was added $(0.1 \mathrm{ml}$ of sulfanilic acid and $200 \mu \mathrm{l}$ naphthylethylenediamine dichloride $(0.1 \%)$ w/v) $)$ and kept on incubation at room temperature for 30 minutes, and finally absorbance is observed at 540nm. All the reactions were performed in triplicates, and their percentage inhibition was calculated by the following formula where 'A' stands for adsorbents:

Inhibition percentage of nitric oxide $=[($ Acontrol-A sample $) /$ Acontrol $)] \times 100$

\section{Hydrogen Peroxide Scavenging Activity $\left(\mathrm{H}_{2} \mathrm{O}_{2}\right)$}

The ability of the extract to scavange hydrogen peroxide was resoluted according to a standard method by Ruch et al.,(1989). The extract $0.1 \mathrm{ml}$ was added to $4 \mathrm{ml}$ of phosphate buffer and mixed with $600 \mu \mathrm{l}$ of $400 \mathrm{~mm}_{2} \mathrm{O}_{2}$. The ability of the extracts to scavenge hydrogen peroxide was determined according to a standard method by Ruch et al., Plant extract $0.1 \mathrm{ml}$ was added to $4 \mathrm{ml}$ of phosphate buffer and mixed with $600 \mu 1$ of $40 \mathrm{~mm} \mathrm{H}_{2} \mathrm{O}_{2}$. Hydrogen peroxide concentration was resolved spectro photometrically at $230 \mathrm{~nm}$ in the absence and presence of the extract. A control was kept without the extract. For each concentrate a different clear containing the concentrate in support arrangement without hydrogen peroxide was utilized. Level of hydrogen peroxide searching (I) was figured as

Inhibition of Hydrogen peroxide $=($ Abs control - Abs test $) /$ Abs control X 1

\section{Ferric Reducing/Antioxidant Power (FRAP) Assay}

The antioxidant capacity of plant extract samples was estimated according to the procedure described by Benzie and Strain (1996). FRAP reagent $(900 \mu \mathrm{l})$, prepared freshly and incubated at $37^{\circ} \mathrm{C}$, was mixed with $90 \mu \mathrm{l}$ of distilled water and $30 \mu \mathrm{l}$ of the test sample, or acetone (for the reagent blank). The test samples and reagent blank were incubated at $37^{\circ} \mathrm{C}$ for 30 minutes in a water bath. The FRAP reagent contained $2.5 \mathrm{ml}$ of 20mmol/1 TPTZ solution (2, 4, 6-Tripyridyltriazine) in $40 \mathrm{mmol} / 1 \mathrm{HCl}$ plus $2.5 \mathrm{ml}$ of $20 \mathrm{mmol} / 1 \mathrm{FeCl} 3.6 \mathrm{H} 2 \mathrm{O}$ and $25 \mathrm{ml}$ of $0.3 \mathrm{~mol} / 1$ acetate buffer, $\mathrm{pH} 3.6$ (Benzie and Strain, 1996). At the end of the incubation period the absorbance readings were recorded immediately at $593 \mathrm{~nm}$ using a spectrophotometer. The known Fe (II) concentration ranging between 100 and 2000 $\mu \mathrm{mol} / 1$ (FeSO4.7H2O) was used for the preparation of the calibration curve. The parameter Equivalent Concentration (EC1) was defined as the concentration of antioxidant has a ferric- TPTZ reducing ability equivalent to that of $1 \mathrm{mmol} / \mathrm{FeSO} 4.7 \mathrm{H} 2 \mathrm{O}$. EC1 was calculated as the concentration of antioxidant giving an absorbance increase in the FRAP assay equivalent to the theoretical absorbance value of a $1 \mathrm{mmol} / \mathrm{l}$ concentration of $\mathrm{Fe}$ (II) solution determined using the corresponding regression equation.

Percentage of inhibition of ferric oxide $=$ Acontrol - Atest $/$ Acontrol X 100

\section{Antibacterial Activity}

To perform an antimicrobial activity using various bacterial and fungal species was selected viz., Escherichia coli, Pseudomonas species, Shigella species, Klebsiella species; Proteus species are bacterial cultures. 


\section{Media and Culture Condition}

Muller-Hinton Agar (MHA), Nutrient Broth (NB) and Luria Britani (LB) were used throughout the study for determining the antibacterial assay. The media were adjusted to the $\mathrm{pH}$

\section{Well Diffusion Method}

The antibacterial activity and antifungal activity of crude extract extracts was determined by the Well Diffusion method (Bauer et al., 1996). MHA plates were prepared by pouring $20 \mathrm{ml}$ of molten media into sterile petri plates. After solidification of media, 20-25 $\mu 1$ suspension of bacterial inoculums was swabbed uniformly. The sterile paper discs were dipped into required solvents then placed in agar plates. Then 10-50 $\mu$ l of plant extract was poured into the wells. After that, the plates were incubated at $37^{\circ} \mathrm{C}$ for 24 hours. The assay was carried into triplicates and control plates were also maintained. Zone of inhibition was measured from the edge of the well to the zone in mm. The tested cell suspension was spread on a Muller Hinton agar plate and potato dextrose agar. Well were put into the agar medium using sterile forceps. Plant extract was poured into wells. Then the plates were incubated at $37^{\circ} \mathrm{C}$ for about 24 hours and control was also maintained. Zone of inhibition was measured from the clear zone in $\mathrm{mm}$.

\section{RESULTS AND DISCUSSIONS}

\section{Estimation of Anti-Oxidant Activity}

DPPH Radical Scavenging Activity

Aqueous and ethanol extracts exhibit scavenging effects when sample concentration is increased. DPPH is a nitrogen - centered free radical. Antioxidants react with DPPH and convert it to a diphenyl- $\beta$-picryl hydrazine. The degree of discoloration indicates the scavenging potentials of the antioxidants. The DPPH scavenging activity of ethanol and aqueous was compared with the activity of the standard. At 500 $\mu \mathrm{g} / \mathrm{ml}$ concentration, the scavenging activity of the standard Ascorbic acid was 65\%, while that of the ethanol and aqueous leaf extract was found to be $79 \%$ and $74.20 \%$ respectively as reported in Tables1. Thus the scavenging activity of the plant extract was more effective than the standard. Phytochemicals especially in plant phenolic constitute a major group of component that act as primary antioxidants (Hatano et al., 1989).

Table 1: DPPH Radicals Scavenging Activity of Carica Papaya Extracts

\begin{tabular}{|c|c|c|c|c|}
\hline S. No & Concentration & Ethanol Extract & Aqueous Extract & Standard (Ascorbic Acid) \\
\hline 1 & $100 \mu \mathrm{l}$ & $32 \%$ & $37.65 \%$ & $25 \%$ \\
\hline 2 & $200 \mu \mathrm{l}$ & $53 \%$ & $43.36 \%$ & $50 \%$ \\
\hline 3 & $300 \mu \mathrm{l}$ & $67 \%$ & $55.32 \%$ & $60 \%$ \\
\hline 4 & $400 \mu \mathrm{l}$ & $76 \%$ & $68 \%$ & $62 \%$ \\
\hline 5 & $500 \mu \mathrm{l}$ & $79 \%$ & $74.20 \%$ & $65 \%$ \\
\hline
\end{tabular}

\section{Nitric Oxide Radical Scavenging Assay}

The Nitric oxide radical scavenging activity of aqueous and ethanol extracts increased with an increase in concentration of the extracts. At $500 \mu \mathrm{g} / \mathrm{ml}$ concentration, the scavenging activity of the standard Ascorbic acid was $87 \%$, while that of the ethanol and aqueous leaf extract was found to be $74 \%$ and $77.05 \%$ respectively as reported in the Tables 2 . Thus the scavenging activity of the plant extract was more effective than the standard. Nitric oxide is a free radical created in cells, associated with physiological process, including neurotransmission, antimicrobial and antitumor exercises. But, overproduction of NO can trigger tissue harm and is related to atherosclerosis and hypertension. Phenolic mixes is 
predominantly because of their redox properties, which can assume vital part in engrossing and killing free radicals (Hepziba et al., 2010).

Table 2: Nitric Oxide Radical Scavenging Assay of Carica Papaya Extracts

\begin{tabular}{|c|c|c|c|c|}
\hline S. No & Concentration & Ethanol Extract & Aqueous Extract & Standard (Ascorbic Acid) \\
\hline 1 & $100 \mu \mathrm{l}$ & $32.76 \%$ & $27.38 \%$ & $26 \%$ \\
\hline 2 & $200 \mu \mathrm{l}$ & $34.53 \%$ & $36.00 \%$ & $47 \%$ \\
\hline 3 & $300 \mu \mathrm{l}$ & $55.05 \%$ & $51.00 \%$ & $52 \%$ \\
\hline 4 & $400 \mu \mathrm{l}$ & $61.30 \%$ & $73.00 \%$ & $69 \%$ \\
\hline 5 & $500 \mu \mathrm{l}$ & $74.00 \%$ & $77.05 \%$ & $87 \%$ \\
\hline
\end{tabular}

\section{Hydrogen Peroxide Scavenging Activity $\left(\mathrm{H}_{2} \mathrm{O}_{2}\right)$}

Ethanolic extract is maximum than in the aqueous extract was found to be $93 \%$ and $72 \%$ respectively, and $\mathrm{H}_{2} \mathrm{O}_{2}$ scavenging activity of standard ascorbic acid was found to be $85 \% . \mathrm{H}_{2} \mathrm{O}_{2}$ is rapidly decomposed into oxygen and water in the body, and this may produce hydroxyl radicals $(\mathrm{OH})$ that can initiate lipid peroxidation and cause DNA damage. The ability of plant extracts to scavenge hydrogen peroxide is determined according to the method of (Ruck et al., 1989). Hydrogen peroxide $\left(\mathrm{H}_{2} \mathrm{O}_{2}\right)$ scavenging action of accepted antioxidants present in plant extracts has been identified broadly (Rajamanikandan et al., 2011).

Table 3: Hydrogen Peroxide Scavenging Activity of Carica Papaya

\begin{tabular}{|c|c|c|c|c|}
\hline S. No & Concentration & Ethanol Extract & Aqueous Extract & Standard \\
\hline 1 & $100 \mu 1 \%$ & $45 \%$ & $36 \%$ & $22 \%$ \\
\hline 2 & $200 \mu 1 \%$ & $58 \%$ & $42 \%$ & $38 \%$ \\
\hline 3 & $300 \mu 1 \%$ & $68 \%$ & $55 \%$ & $54 \%$ \\
\hline 4 & $400 \mu 1 \%$ & $79 \%$ & $67 \%$ & $69 \%$ \\
\hline 5 & $500 \mu 1 \%$ & $93 \%$ & $72 \%$ & $87 \%$ \\
\hline
\end{tabular}

The active chemical constituents of plant extract like essential oils, amino acids, tanins, uric acid etc., are responsible for Hydrogen peroxide $\left(\mathrm{H}_{2} \mathrm{O}_{2}\right)$ scavenging activity (Srijayanth et al., 1999).

\section{Ferric Reducing/Antioxidant Power (FRAP) Assay}

The antioxidant potential of Carica papaya leaves, the aqueous and ethanol extract was ascertained from FRAP assay based on their ability to reduce TPTZ-Fe(III) complex to TPTZ-Fe(II). The reducing ability of aqueous and ethanol extract with varying concentration $(20-100 \mu \mathrm{g} / \mathrm{ml})$ was examined and compared with standard ascorbic acid. The maximum scavenging activity was found in the ethanol extract to be $86 \%$ and $83 \%$. respectively reported in the Table 4 .

Table 4: Ferric Reducing Antioxidant Power of Carica Papaya Extract

\begin{tabular}{|c|c|c|c|c|}
\hline S. No & Concentration & Ethanol Extract & Aqueous Extract & Standard \\
\hline 1 & $100 \mu \mathrm{l}$ & $21 \%$ & $22 \%$ & $33 \%$ \\
\hline 2 & $200 \mu \mathrm{l}$ & $30 \%$ & $28 \%$ & $44 \%$ \\
\hline 3 & $300 \mu \mathrm{l}$ & $69 \%$ & $52 \%$ & $52 \%$ \\
\hline 4 & $400 \mu \mathrm{l}$ & $82 \%$ & $81 \%$ & $71 \%$ \\
\hline 5 & $50 \mu \mathrm{l}$ & $87 \%$ & $84 \%$ & $83 \%$ \\
\hline
\end{tabular}

The phenolic acid and flavonoids are very much responsible for the ferric reducing ability mainly in many of the plant extract (Maruthamuthu et al., 2016). 


\section{Antibacterial Activity}

The antibacterial activity of aqueous and ethanolic extract was reported in the Table 5. The result showed that $E$. coli sp was susceptible both in aqueous and ethanol extract at $100 \mathrm{mg} / \mathrm{ml}$ concentration and zone of inhibition was $26 \mathrm{~mm}$ and $28 \mathrm{~mm}$ respectively. Shigella sp being the most susceptible at $100 \mathrm{mg} / \mathrm{ml}$ concentration of ethanol extract and zone of inhibition was $30 \mathrm{~mm}$. Klebsiella sp had added susceptibility at $100 \mathrm{mg} / \mathrm{ml}$ concentration of aqueous extract and zone of inhibition was $30 \mathrm{~mm}$, while the Pseudomonas sp., was liable at $100 \mathrm{mg} / \mathrm{ml}$ concentration of aqueous extract and zone of inhibition was $23 \mathrm{~mm}$. The secondary metabolites in a number of plant extracts are mainly responsible for antimicrobial, antifungal and anticancer activity (Compean and Ynalvez, 2014).

Table 5: Antibacterial Activity of Enteric Bacteria Isolates

\begin{tabular}{|l|c|c|c|c|c|}
\hline \multicolumn{1}{|c|}{ Test Organism } & \multicolumn{2}{|c|}{ Ethanol Extract } & \multicolumn{2}{c|}{ Aqueous Extract } & Control (Chloramphenicol) \\
\hline & $50 \mathrm{mg} / \mathrm{ml}$ & $100 \mathrm{mg} / \mathrm{ml}$ & $50 \mathrm{mg} / \mathrm{ml}$ & $100 \mathrm{mg} / \mathrm{ml}$ & \\
\hline E. coli & $20 \mathrm{~mm}$ & $26 \mathrm{~mm}$ & $22 \mathrm{~mm}$ & $28 \mathrm{~mm}$ & $20 \mathrm{~mm}$ \\
\hline Shigella & $28 \mathrm{~mm}$ & $30 \mathrm{~mm}$ & $25 \mathrm{~mm}$ & $28 \mathrm{~mm}$ & $32 \mathrm{~mm}$ \\
\hline Klebsiella sp., & $10 \mathrm{~mm}$ & $28 \mathrm{~mm}$ & $25 \mathrm{~mm}$ & $30 \mathrm{~mm}$ & $28 \mathrm{~mm}$ \\
\hline Pseudomonas sp., & $20 \mathrm{~mm}$ & $15 \mathrm{~mm}$ & $16 \mathrm{~mm}$ & $23 \mathrm{~mm}$ & $20 \mathrm{~mm}$ \\
\hline
\end{tabular}

\section{CONCLUSIONS}

Antioxidant and antimicrobial property of Ethanol extract and Aqueous extract of Carica papaya leaves were investigated in this study. They can be considered as a natural source to control the enteric pathogen. During a time of rapidly rising antibiotic resistance, new approaches are necessary to fill antimicrobial drug development. Plants remain a unique and underexploited source of bioactive compounds and botanical research tools can be used to guide for future research efforts. To reduce the side effects of the usage of synthetic drugs, we can use medicinal plants for the treatment of common diseases. However, further studies are needed to obtain purified compounds that may be responsible for the activities observed from the tested leaves.

\section{REFERENCES}

1. Bauer. A. W., Kirby. W. M., Sherris. J. C. and Turck. M. (1996). Antibiotic susceptibility testing by standardized single disc method. Am. J. Clin Pathol., 44: 493-496.

2. Benzie, I. F. F., and Strain, J. J. (1996). The ferric reducing ability of plasma (FRAP) as a measure of "antioxidant power"; The FRAP assay, Analytical Biochemistry, 239(1): 70-76.

3. Bouayed, H., Rammal, A., Dicko, C. and Yonos, R. (2007) Chlorogenic acid, a polyphenol from Prunus domestica (Mirabelle), with coupled anxiolytic and antioxidant effects, J. Neurol. Sci., 262. 77-84

4. Braca, A., Tommasi, N. D. and Bari, L. D. (2001). Antioxidant principles from Bauhinia terapotensis. J Nat Prod., 64: 892895

5. Cappuccino. G, and Sherma, N. 2014. Microbiology a laboratory manual. $10^{\text {th }}$ edition.

6. Compean, K. L. and Ynalvez, R. A. 2014. Antimicrobial Activity of Plant Secondary Metabolites: A Review. Research Journal of Medicinal Plants, 8: 204-213.

7. Garratt, D. C. (1964): The quantitative analysis of Drugs. Volume 3. Chapman and Hall ltd, Japan; 456-458.

8. Kareem, K. A., \& Ali, W. D. A. In-Vitro Evaluation Of Antibacterial Activity Of Silybum Marianum Seeds Oil, Ethanolic Extract And Antibiotics Against Isolated Bacteria. 
9. Garrod, L. P., Lambert, H. P. and Gray, F. (1995). Antibiotics and Chemotherapy, 4th Ed, Churchill, Livingstons, Edinburgh, London and New York. 501-512.

10. Hatano, T., Edamatsu, R., Hiramatsu, M., Mori A. and Fujita, Y. (1989). Effects of the interaction of tannins with co-existing substances and effects of tannins and related polyphenols on superoxide anion radical and on 1,1-diphenyl-2-picrylhydrazyl radical. Chem. Pharm. Bull. 37:2016-2021.

11. Hepsibha, B. T., Sathiya, S. Babu, C. S., Premalakshmi, V and Sekar, T. (2010) In vitro studies of antioxidant and free radical scavenging activities of Azima tetracantha. Lam leaf extract. Indian J Sci Technol; 3:571-577.

12. Omojasola, P. F. and Awe, S. (2004). The Antibacterial activity of the leaf extract against some selected microorganisms. Bioscience Research Communication 16 (1).

13. Oyelola, O. (2005): Evaluation of the hypoglycemic activity of Treculia Africana Decne (root) in normal and diabetic rats. M. Pharm (Clinical Pharmacy) Dissertation.

14. Mukhar, M. D. and Tukur, A. (1999) In-vitro screening for activity of Pistia stratiotes extracts. NISEB J I 1:51-60.

15. Rajamanikandan, S., Sindhu, T., Durgapriya, D., Sophia, D., Ragavendran P., Gopalakrishnan, V. K. (2011) Radical scavenging and antioxidant activity of ethanolic extract of Mollugo nudicaulis by in vitro assays. Indian J. Pharm. Educ. Res., 45(4):310-316.

16. Ruch, R. J., Cheng, S. J. and Klaunig, J. E. (1989) Prevention of cytotoxicity and inhibition of intercellular communication by antioxidant catechins isolated from Chinese green tea. Carcinogenesis., 10(6):1003-8.

17. Srijayanth, S., Raman, A. and Goodwin, B. l. (1999) A comparative study of the Constituent of Aesculusindica, J Med Food, 2(2), $45-50$. 
